Acta Theriologica 45, Suppl. 1: 11-17, 2000.

PL ISSN 0001-7051

\title{
New chromosome races of the common shrew Sorex araneus from Eastern Siberia
}

\author{
Andrei V. POLYAKOV, Jan ZIMA, Agata BANASZEK, \\ Jeremy B. SEARLE and Pavel M. BORODIN
}

\begin{abstract}
Polyakov A. V., Zima J., Banaszek A., Searle J. B. and Borodin P. M. 2000. New chromosome races of the common shrew Sorex araneus from Eastern Siberia. [In: Evolution in the Sorex araneus group: Cytogenetic and molecular aspects. J. B. Searle and J. M. Wójcik, eds]. Acta Theriologica 45, Suppl. 1: 11-17.

Two new chromosome races of the common shrew Sorex araneus Linnaeus, 1758 have been discovered in Eastern Siberia (Strelka and Ilga). This finding helps to clarify the geographical limits of other previously-described chromosome races (Tomsk and Baikal) in the same region and to elucidate the chromosome evolution of Siberian common shrews. The diversity of chromosome races in this area can be explained by stepwise accumulation of Robertsonian fusions and whole-arm reciprocal translocations from a Baikal-like ancestral race.

Institute of Cytology and Genetics, Russian Academy of Sciences, Lavrentiev ave. 10, Novosibirsk 630090, Russia, e-mail: polyakov@bionet.nsc.ru, borodin@bionet.nsc.ru (AVP, PMB); Institute of Vertebrate Biology, Academy of Sciences of the Czech Republic, Květná 8, CZ-603 65 Brno, and Department of Zoology, Faculty of Science, Charles University, Viničná 7, CZ-128 44 Praha, Czech Republic, e-mail: jzima@brno.cas.cz (JZ); Institute of Biology, University of Białystok, Świerkowa 20B, PL 15-950 Białystok, Poland, e-mail: banaszek@cksr.ac.bialystok.pl (AB); Department of Biology, University of York, P.O. Box 373, York YO10 5YW, U.K., e-mail: jbs3@york.ac.uk (JBS)
\end{abstract}

Key words: Sorex araneus, chromosome races, Robertsonian fusions, whole-arm reciprocal translocations

\section{Introduction}

The common shrew Sorex araneus Linnaeus, 1758 demonstrates remarkable inter-population chromosome variation in terms of existence of chromosome races (review: Searle and Wójcik 1998). The full haploid karyotype of this species consists of 18 autosome arms, 12 of which are involved in this racial variation. More than 50 chromosome races have been described (Zima et al. 1996) and they are believed to be formed in two ways. One way is through fixation of multiple Robertsonian (Rb) fusions. Alternatively, one chromosome race may evolve into another following modification of metacentrics by whole-arm reciprocal translocations (WARTs) (Winking 1986). It has been suggested that WARTs can generate large series of chromosome races from a single ancestor (Halkka et al. 1987, 1994, Wójcik 1993, Fredga 1996, Polyakov et al. 1997b). 
To further our understanding of the generation of chromosome races in the common shrew, it is desirable to study the species over its whole range. One part of the range that is relatively poorly known is Eastern Siberia, which forms the extreme eastern limit of the species. Only two localities have been studied there before, those that define the Yermakovskoie and Baikal races (Aniskin and Volobouev 1981, Zima et al. 1994; Fig. 1). In this paper we present data on shrews from three new sites and define two new races. These results add significantly to our knowledge of chromosome variation in the Asian part of the range of the common shrew and permit us to devise an evolutionary scheme for the chromosome races in that area.

\section{Material and methods}

Common shrews were caught with live traps in the years 1995-1996 at 3 localities shown in Fig. 1. The specimens studied and their geographic origin are shown in Table 1. Chromosome spreads were made in the field from bone marrow (Král and Radjabli 1974, Polyakov et al. 1997a). G-band staining was performed in the laboratory according to Radjabli and Kryukova (1973). Chromosome nomenclature follows Searle et al. (1991).

\section{Results and discussion}

Since 1995 the population density of the common shrew in Siberia has apparently been low (Polyakov et al. 1997a), especially in the marginal eastern areas of the species range. We only managed to obtain samples in a few trapping sites and the sample sizes were small. Here we present data on the three sites where we found two new races: the Ilga and the Strelka.

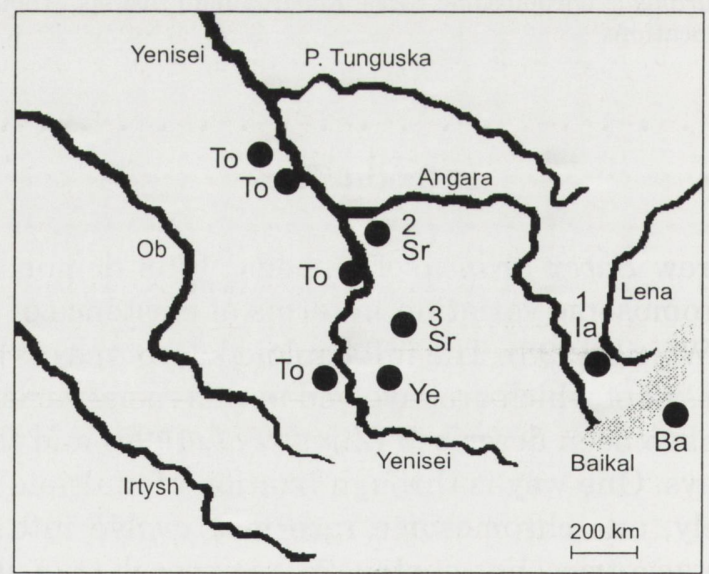

Fig. 1. Map showing the collection sites for the present study (labelled 1-3) and sites where the Baikal (Ba) and Yermakovskoie (Ye) races were previously collected (Aniskin and Volobouev 1981, Zima et al. 1994). The easternmost localities of the Tomsk race (To) are also shown (Polyakov et al. 1996). 


\section{Ilga race}

The easternmost site 1 (Fig. 1) was situated north of the Lake Baikal by the Ilga river near the village of Zhigalovo. One of two males from this site was homozygous for metacentric chromosomes $g k, h o, i m, j l, n q$ and homozygous for acrocentrics $p$ and $r$; the other was heterozygous for $g k$ (Table 1, Fig. 2). This is a new combination of metacentrics and, following the definition of chromosome races provided by Hausser et al. (1994), we tentatively define the Ilga race as follows:

Ilga race (Ia)

$\mathrm{XX} / \mathrm{XY}_{1} \mathrm{Y}_{2} a f, b c, g / k, h o, i m, j l, n q, p, r, t u$

Description: this paper

Type locality: Zhigalovo, E Siberia, Russia $54^{\circ} 45^{\prime} \mathrm{N}, 104^{\circ} 56^{\prime} \mathrm{E}$

Distribution: Type locality

\section{Strelka race}

Trapping sites 2 and 3 were located near the city of Strelka and the village of Narva on the right bank of the Mana river (right tributary of Yenisei), respectively (Fig. 1, Table 1). At these two sites we trapped 5 shrews characterised by metacentrics go, $h i$ and $j l$ (Fig. 2), which again is a new combination for Eastern Siberia. We describe this as the Strelka race:

Strelka race $(\mathrm{Sr})$

$\mathrm{XX} / \mathrm{XY}_{1} \mathrm{Y}_{2} a f, b c, g / o, h i, j l, k, m, n, p, q, r, t u$

Description: this paper

Type locality: Strelka, E Siberia, Russia $58^{\circ} 07^{\prime} \mathrm{N}, 93^{\circ} 30^{\prime} \mathrm{E}$

Distribution: E Siberia, right bank of the Yenisei river

The Tomsk race is characterized by metacentrics $g k, h i, j l, m n$ and $q r$ and occupies the left bank of Yenisei river (Polyakov et al. 1996, Fig. 1). A male from site 2 with the karyotype $g k / g o / k / o, q / r$ was likely a Strelka $\times$ Tomsk hybrid, confirming its location at the contact of the two races. Apparently, the Yenisei river marks an eastern border of the Tomsk race. Indeed, on the left bank of Yenisei we found the

Table 1. Karyotypes of the common shrews collected in different localities of eastern Siberia. ${ }^{*}-$ the site codes are given in accordance with those in Fig. 1, M - male, F-female.

\begin{tabular}{clll}
\hline Site and coordinates & Sex and $2 \mathrm{n}$ & \multicolumn{1}{c}{ Karyotype } & Race \\
\hline 1. Zhigalovo* & $1 \mathrm{M}, 2 \mathrm{n}=23$ & gk, ho, $i m, j l, n q, p, r$ & Ilga \\
$54^{\circ} 45^{\prime} \mathrm{N}, 1^{\circ} 4^{\circ} 56^{\prime} \mathrm{E}$ & $1 \mathrm{M}, 2 \mathrm{n}=24$ & $g / k, h o, i m, j l, n q, p, r$ & Ilga \\
2. Strelka & $1 \mathrm{M}, 2 \mathrm{n}=28$ & $g / o, h i, j l, k, m, n, p, q, r$ & Strelka \\
$58^{\circ} 07^{\prime} \mathrm{N}, 93^{\circ} 30^{\prime} \mathrm{E}$ & $1 \mathrm{M}, 2 \mathrm{n}=27$ & $g o, h i, j l, k, m, n, p, q, r$ & Strelka \\
& $1 \mathrm{M}, 2 \mathrm{n}=26$ & $g k / g o / k / o, h i, j l, q / r, m, n, p$ & Strelka $\times$ Tomsk hybrid \\
& $1 \mathrm{M}, 2 \mathrm{n}=27$ & $g o, h i, j l, k, m, n, p, q, r$ & Strelka \\
3. Narva & $2 \mathrm{~F}, 2 \mathrm{n}=26$ & $g o, h i, j l, k, m, n, p, q, r$ & Strelka \\
$55^{\circ} 26^{\prime} \mathrm{N}, 93^{\circ} 44^{\prime} \mathrm{E}$ & & & \\
\hline
\end{tabular}


a)

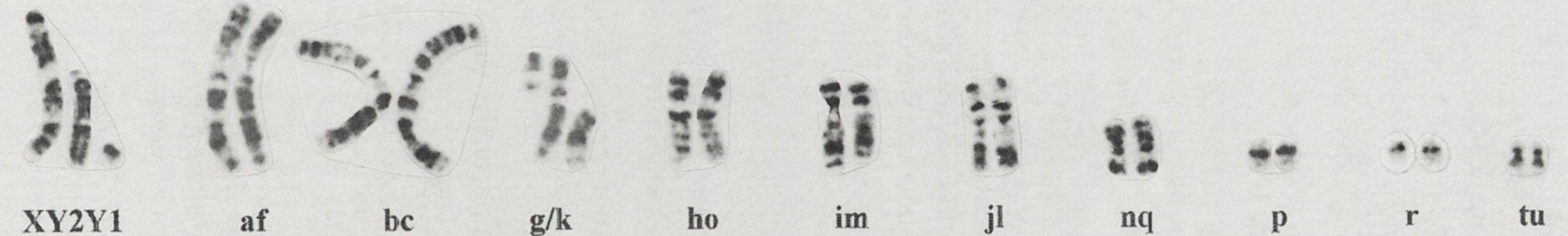

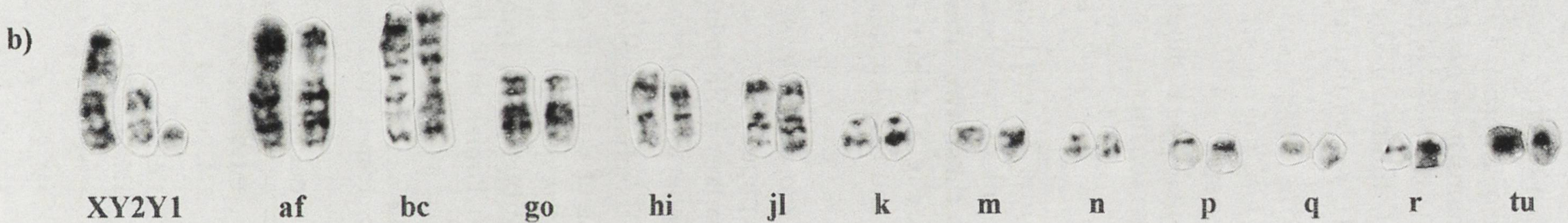


Tomsk race in all three sites studied (Polyakov et al. 1996). Earlier Aniskin and Volobouev (1981) also described one more site with Tomsk race individuals from the left bank. On the right bank we found the Strelka race at two sites (Fig. 1) and Aniskin and Volobouev (1981) described the Yermakovskoie race at one site. Finding a Strelka $\times$ Tomsk hybrid on the right bank of Yenisei indicates that the migration of shrews across the river is possible at least at site 2 .

\section{Pattern of chromosomal evolution in Siberia}

The discovery of two new chromosome races in Eastern Siberia allows us to reconsider the chromosomal evolution of common shrews in Siberia overall. Of the races that have been described so far, the Baikal has the fewest metacentrics and can be considered closest to the ancestral condition (Zima et al. 1994). Among the variable chromosomes only $h i$ and $j l$ are present as metacentrics. Starting with this race it is possible to derive all the other races by assuming that races evolve from neighbouring ancestral forms by stepwise accumulation of Rb fusions and WARTs (Fig. 3). Such accumulation could accompany range changes in association with the last glaciation and its ending. For example, on range expansion at the end of the glaciation, a metacentric (formed by Rb fusion or a WART) may become fixed at the leading edge. The new race formed will become the new leading edge, which may

\section{Novosibirsk Introgression qr}

go, hn, ik, jl, mp, qr

Baikal

$g, h i, j l, k, m, n, o, p, q, r$

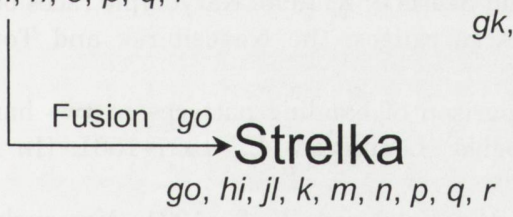

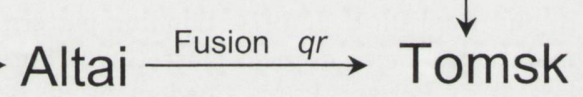

gk, hi, jl, mn, o, p, q, r gk, hi, jl, mn,o,p, qr
Yermakovskoie

$g k$, ho, $i, j l, m n, p, q, r$

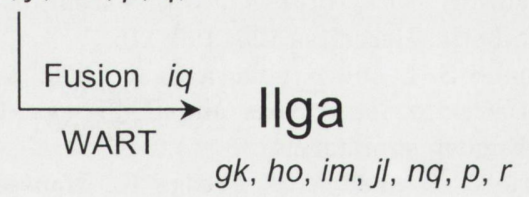

Fig. 3. Tentative scheme for the evolution of chromosome races of the common shrew in Siberia. The Baikal race has the fewest metacentrics and is considered the ancestral form. In this scheme, neighbouring races can be derived from each other by one or two Rb fusions and/or WARTs. The Tomsk race is thought to have derived metacentric $q r$ by introgression from the neighbouring Novosibirsk race or by fusion of acrocentrics at the northern edge of the range of the Altai race (Polyakov et al. 1996). 
itself be the site of fixation of a second metacentric, generating a second new race, and so on.

Clearly, much more work is required to confirm the evolutionary scheme in Fig. 3. Substantially more chromosome survey work is required to establish the widespread occurrence of the Strelka, Ilga and other chromosome races. Molecular studies are needed to provide a phylogeographic framework for the chromosome variation (work in progress) and, if possible, to demonstrate particular chromosomal rearrangements that have been hypothesised.

Acknowledgements.: We thank V. Panov, M. Bochkarev and T. Ladygina for their invaluable help in collecting shrews. We are also grateful to V. T. Volobouev for his comments on the manuscript. The study was supported by grants from INTAS (No. 93-1463), Russian Foundation for Basic Research (No. 95.04-12698 and 96-15-97738), and in part by the Ministry of Education of the Czech Republic (No. VS97102).

\section{References}

Aniskin V. M. and Volobouev V. T. 1981. [Chromosome polymorphisms in Siberian populations of shrews of araneus-arcticus complex (Insectivora, Soricidae). Three chromosome forms of the common shrew Sorex araneus L.]. Genetika 17: 1784-1791. [In Russian]

Fredga K. 1996. The chromosome races of Sorex araneus in Scandinavia. Hereditas 125: 123-135.

Halkka L., Kaikusalo A. and Vakula N. 1994. Revision of Sorex araneus L. chromosome nomenclature, and race N new to Finland. Annales Zoologici Fennici 31: 283-288.

Halkka L., Söderlund V., Skarén U. and Heikkilä J. 1987. Chromosomal polymorphism and racial evolution of Sorex araneus L. in Finland. Hereditas 106: 257-275.

Hausser J., Fedyk S., Fredga K., Searle J. B., Volobouev V., Wójcik J. M. and Zima J. 1994. Definition and nomenclature of the chromosome races of Sorex araneus. Folia Zoologica 43, Suppl. 1: 1-9.

Král B. and Radjabli S. I. 1974. Banding patterns and Robertsonian fusions in the western Siberian population of Sorex araneus (Insectivora, Soricidae). Folia Zoologica 23: 217-227.

Polyakov A. V., Borodin P. M., Chadova N. B., Rodionova M. I., Panov V. V., Dobrotvorsky A. K. and Searle J. B. 1997a. Novosibirsk revisited 24 years on: chromosome polymorphism in the Novosibirsk population of the common shrew Sorex araneus L. Heredity 79: 172-177.

Polyakov A. V., Borodin P. M., Lukáčová L., Searle J. B. and Zima J. 1997b. The hypothetical Old-Northern chromosome race of Sorex araneus found in the Ural Mts. Annales Zoologici Fennici 34: 139-142.

Polyakov A. V., Borodin P. M., Volobouev V. T. and Searle J. B. 1996. Karyotypic races of the common shrew (Sorex araneus) with exceptionally large ranges: the Novosibirsk and Tomsk races of Siberia. Hereditas 125: 109-115.

Radjabli S. I. and Kryukova E. P. 1973. A comparison of banding patterns in two hamster species Cricetulus barabensis and C. griseus. Citologiya (Leningrad) 15: 1527-1531. [In Russian with English summary]

Searle J. B., Fedyk S., Fredga K., Hausser J. and Volobouev V. T. 1991. Nomenclature for the chromosomes of the common shrew (Sorex araneus). Mémoires de la Société Vaudoise des Sciences Naturelles 19: 13-22.

Searle J. B. and Wójcik J. M. 1998. Chromosomal evolution: the case of Sorex araneus. [In: Evolution of shrews. J. M. Wójcik and M. Wolsan, eds]. Mammal Research Institute, Polish Academy of Sciences, Białowieża: 219-268.

Winking H. 1986. Some aspects of Robertsonian karyotype variation in European wild mice. Current Topics of Microbiology and Immunology 127: 68-74. 
Wójcik J. M. 1993. Chromosome races of the common shrew Sorex araneus in Poland: a model of karyotype evolution. Acta Theriologica 38: 315-338.

Zima J., Fedyk S., Fredga K., Hausser J., Mishta A., Searle J. B., Volobouev V. T. and Wójcik J. M. 1996. The list of the chromosome races of the common shrew (Sorex araneus). Hereditas 125: 97-107.

Zima J., Macholán M., Filippucci M. G., Reiter A., Andreas M., Lípa M. and Kryštufek B. 1994. Karyotypic and biochemical status of certain marginal populations of Sorex araneus. Folia Zoologica 43, Suppl. 1: 43-51.

Received 29 September 1999, accepted 6 March 2000. 